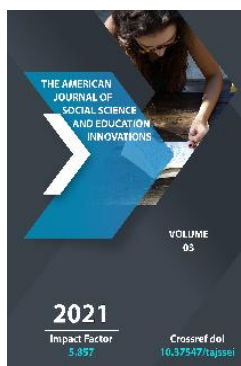

\title{
Logopeed's Code Of Ethics
}

\author{
B.X.Khusniddinova \\ Teacher Of Tashkent State Pedagogical University, Tashkent, Uzbekistan
}

Journal Website:

http://theamericanjour

nals.com/index.php/taj

ssei

Copyright: Original content from this work may be used under the terms of the creative commons attributes 4.0 licence.

\section{ABSTRACT}

The article is about a creative approach to the organization of professional activity, self-discipline, the desire to enrich their professional knowledge and improve their pedagogical skills, to establish a respectful and demanding relationship with students and their parents, a positive solution to complex pedagogical conflicts mastering the skills of making.

\section{KEYWORDS}

Skill, pedagogical skill, components of pedagogical skill, pedagogical deontology, communicative competence of a teacher, types of pedagogical communication, methods of pedagogical communication, pedagogical politeness (tact), dispute, pedagogical dispute, types of pedagogical dispute, methods of resolving pedagogical conflict.

\section{INTRODUCTION}

In the last decade, Russian speech therapy has been intensively developing, innovative areas of correctional and pedagogical work are emerging, new methods of correcting complex

speech disorders are being developed and implemented, experts are discussing the 
factors affecting the success of speech therapy correction.

A comparative analysis and generalization of the available scientific data indicates that the success of speech therapy work depends not only on the degree of the specialist's proficiency in speech therapy technologies, but also on whether he is able to adequately assess his own professional activity and properly interact with other participants in the correction and development process ( by the administration of the educational institution, colleagues, pupils (preschoolers and schoolchildren), parents (legal representatives)).

\section{MATERIAL AND METHODS}

The main goal of this Code of Ethics (hereinafter referred to as the Code), the provisions of which apply to all types of professional activities of a speech therapist in the education system in Uzbekistan, is to determine the fundamental rights and obligations arising from the characteristics of professional activities, to establish ethical relationships between all participants in the educational process. For the systematic implementation of the objectives of this Code, it is necessary to solve a number of tasks, namely:

- Determination of ethical principles of behavior of participants in the educational process;

- Establishing the basis for regulating the behavior of participants in the educational process in complex (or non-standard) ethical situations;

- Ensuring the awareness of the participants in the educational process of their personal responsibility for the performance of professional duties;
- Increasing the level of culture of relationships between participants in the educational process, implemented in an educational institution;

- Formation of a positive microclimate in the team;

- Assistance in the fulfillment of the mission and achievement of the strategic goals of the educational institution.

The scope of the Code is the sphere of relations between the participants in the educational space, as well as the area of interaction with representatives of government authorities, the public and the media.

The Code confirms the aspiration of participants in the educational process to a high level of culture of relationships in their daily activities. Teacher-speech therapist in professional activity is guided by the principles and rules of conduct contained in the Code.

\section{DISCUSSION AND CONCLUSION}

The Code should serve as a teacher-speech therapist as a guideline when planning and building work with a client, when resolving problem and conflict situations that arise in the process of professional activity; is intended to protect clients from the undesirable consequences of uncontrolled and unskilled use of specialized knowledge, as well as to protect speech therapists and practical speech therapy teachers from discrediting. Basic ethical principles of the speech therapist teacher

1. The principle of humanistically oriented content.

2. The principle of anthropocentricity.

3. The principle of competence.

4. The principle of pedagogical support. 
5. The principle of subjectivity.

6. The principle of an individual approach.

7. The principle of the activity approach.

1. The principle of the humanistically oriented content of correctional and developmental impact obliges the speech therapist teacher to develop a correctional and developmental strategy in each specific case, based on the recognition of the personality of the speech pathologist as the highest value and goal of socially significant activity, which is the development of speech; to clarify the developmental trajectory that provides conditions not only for mastering a specific set of speech knowledge and skills, but also for the formation of certain value orientations, moral attitudes and personal qualities.

2. The principle of anthropocentricity, which provides comfortable, conflict-free and safe conditions for raising a child's individuality in the course of the correctional and developmental process, taking into account the child's real capabilities, realizing his natural potential, updating the vitagenic experience, creating a situation in which the child's personality is a priority subject of the educational space.

3. The principle of competence, in accordance with which the speech therapist teacher determines and takes into account the framework of his own competence on the basis of introspection, self-development, indicators of professional culture, ensures the purposeful continuity of the content and technological renewal of professional tools, is responsible for the expediency of actions in the system of correctional and developmental influence, the choice of procedures and methods of working with the client.

4. The principle of pedagogical support involves the creation of a humane and culturally consistent environment for the formation of an actively individual personality; the development by a speech therapist of a system of pedagogical developmental, supportive and educational actions focused on supporting personal success, updating personal qualities, minimizing the child's difficulties in the correctional and developmental process.

5. The principle of subjectivity implies the implementation of a subjective position by a speech therapist in the process of interacting with a child, reflecting a respectful attitude, understanding of problems, the ability of a speech therapist to stimulate a child to be independent in correcting mistakes in the course of the correctional and developmental process, to awaken the child's faith in the success of his own activities.

6. The principle of an individual approach ensures the creation of a comfortable developmental and compensatory environment, taking into account the individual characteristics of children of preschool and school age (the nature of speech disorders and their personal developmental characteristics), as well as typological characteristics inherent in children with speech disorders. An individual approach allows you to use a system of methods and means of support, depending on the specifics of the development of children, their ability to correct speech disorders and compensation.

7. The principle of the activity approach makes it possible to define the correctional and developmental process 
as a whole as a joint type of activity of a speech therapist and a child on the basis of cooperation, communication and communication, and the pedagogical activity of a speech therapist, organizing the process of prevention, development and correction of speech disorders, as a humane teaching and supporting activities in particular.

General style of solving conflict situations

This Code does not describe all possible conflicts of interest that may arise during the implementation of the correctional and developmental process by a speech therapist teacher. Its provisions should be resorted to in situations where the personal interest of one participant in the educational process, of which correctional and developmental activities are a part, clearly contradicts the interests of others or the educational institution as a whole.

All participants in the correctional and developmental process strive to carry out conflict-free activities and respect each other. Areas of potential conflicts are promptly identified, reduced to a minimum and placed under strict control.

Acknowledgement. Code of pedagogical ethics of a speech therapist:

1. Go to the children with a smile. Smiling relieves tension and anxiety that almost always arise in children when interacting with an adult.

2. First teach, then demand.

3. Be fair in assessing the knowledge and behavior of children.

4. Keep your word to the children.

5. Protect your child from all kinds of arbitrariness.
6. Strictly keep children's secrets.

7. Be discreet and patient. Never stoop to humiliation and insult of children, and they will never insult or humiliate you.

8. Be an example in everything: in work, in clothing, in behavior.

9. Never demand from children what you don't do yourself.

10. In any situation, be able to put yourself in the place of the pupil.

11. Remember: you can understand a child only when you love him.

12. Don't stop learning for a minute. Be attentive and you will learn a lot from your colleagues and from your students

13. Never complain about your students. Remember: a good teacher is only dissatisfied with himself.

14. Do not compare children: in some it develops envy and anger, in others flattery and hypocrisy.

15. Trust your children. Give up petty tutelage in your relationship with them.

16. Be generous to someone who accidentally stumbles.

17. If you are wrong, ask the pupil for forgiveness. This will not diminish your authority in the least.

18. Find the good even in the most careless child. Try to raise him up in your own eyes, and he will live up to your hopes

19. Live in the interests of children, and you will understand that the joy of close communication with children is one of the most earthly joys. 
20. Go to work as if on a holiday, otherwise you have nothing to do there..

\section{REFERENCES}

1. Babansky Yu.N. Problems of increasing the effectiveness of pedagogical research. - $M$ .: Pedagogy, 1982 - 188s.

2. Bakhtin M.M. Aesthetics of verbal creativity. Moscow: Art, 1986 .-- 444p.

3. Beilinson JI.C. Professional speech of a speech therapist. - M .: "TC Sphere", 2005 $159 \mathrm{p}$.

4. Belova-David P.A. On the joint work of the staff of the speech department with the parents of children suffering from severe forms of speech underdevelopment // Abstracts of the IV All-Union Pedagogical Readings.-M. 1976-C. 106-107.

5. Burak E.H., Tenyanko M.Yu. About deontological and legal training of MGMI students / Healthcare. - 1998. No. 9- P.3741.

6. Bystrova G.A. Speech therapy in dialogues. SPb .: KARO, 2004 - $112 \mathrm{~S}$.

7. Debrovich A.B. Educator about psychology and psychohygiene of communication: $A$ book for teachers and parents. - M., 1987 3115.

8. Drozdov V.N. Deontological studies; Kirov, Phil. Perm. honey. in-that. Kirov, 1994 - 112 p. 